\title{
Evaluation of the efficacy of a topical chamomile-pumpkin oleogel for the treatment of plaque psoriasis: an intra-patient, double-blind, randomized clinical trial
}

\author{
Sima Kolahdooz ${ }^{1 \odot}$, Mehrdad Karimi $^{2},{ }^{\circledR}{ }^{\circledR}$, Nafiseh Esmaili $^{3}{ }^{\circledR}$, Arman Zargaran $^{4 \odot}$, Gholamreza Kordafshari ${ }^{5 \odot}$, \\ Nikoo Mozafari ${ }^{6 \odot}$, Mohammad. Hossein Ayati $^{7 \oplus}$
}

\begin{abstract}
${ }^{1}$ Department of Iranian Traditional Medicine, School of Iranian Traditional Medicine, Tehran University of Medical Sciences, Tehran, Iran

${ }^{2}$ Department of Iranian Traditional Medicine, School of Iranian Traditional Medicine, Tehran University of Medical Sciences, Tehran, Iran

${ }^{3}$ Autoimmune Bullouse Diseases Research Center, Razi Hospital, Tehran University of Medical Sciences, Tehran, Iran
\end{abstract}

${ }^{4}$ Department of Traditional Pharmacy, School of Iranian Traditional Medicine, Tehran University of Medical Sciences, Tehran, Iran

${ }^{5}$ Department of Iranian Traditional Medicine, School of Iranian Traditional Medicine, Tehran University of Medical Sciences, Tehran, Iran

Correspondence

Mehrdad Karimi, Department of Iranian Traditional Medicine, School of Iranian Traditional Medicine, Tehran University of Medical Sciences, Tehran, Iran

Email: mehrdadkarimi@yahoo.com History

- Received: 13 September 2018

- Accepted: 15 October 2018

- Published: 19 November 2018

DOI :

https://doi.org/10.15419/bmrat.v5i11.499

\section{Check for updates}

Copyright

(c) Biomedpress. This is an openaccess article distributed under the terms of the Creative Commons Attribution 4.0 International license.

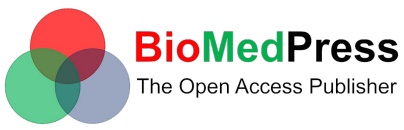

\begin{abstract}
Background: Plaque psoriasis is a chronic inflammatory skin disease. Conventional treatments of psoriasis are not completely effective. In addition, unwanted side effects limit their long-term use. In this regard, developing new natural treatments with fewer side effects could be an alternative option. This study was designed to evaluate the efficacy and safety of topical chamomile-pumpkin oleogel (ChP) in treating plaque psoriasis. Methods: A total of 40 patients with mild-to-moderate plaque psoriasis were enrolled in this intra-patient, double-blind, block-randomized clinical trial. In each patient, bilateral symmetrical plaques were treated with ChP or placebo twice daily for four weeks. For clinical assessment, the Psoriasis Severity Index (PSI) and the Physician's Global Assessment (PGA) scale were evaluated at baseline and after the treatment. At the end of the study, patients' satisfaction with the treatment was evaluated using a visual analog scale (VAS) ranging from 0 to 10. For safety assessment, all treatment-related side effects were recorded. Results: Thirty-seven subjects (20 female, 17 male; age 20-60 years) completed the study. The mean decreases in the PSI score in the ChP group (4.09 \pm 2.24$)$ were significantly $(p=0.000)$ greater than the placebo group $(0.48 \pm 1.39)$. According to the PGA results, $13 / 37$ (35\%) of the ChP-treated plaques could achieve marked to complete improvement compared to $0 \%$ in the placebo group. Three patients dropped out from the study due to worsening of bilateral plaques during the first week of trial. Conclusion: Our results suggest that topically applied ChP could provide a safe and effective complementary option for psoriasis plaque management. IRCT registration code: IRCT2016092830030N1.
\end{abstract}

Key words: Plaque psoriasis, Chamomile, Pumpkin

\section{INTRODUCTION}

Psoriasis is a chronic and complex autoimmune skin disease with a prevalence of $2-4 \%$ in the world ${ }^{1}$. The most prevalent (up to 90\%) sub-type of this disease is plaque psoriasis, which is characterized by raised erythematous scaly skin patches ${ }^{2}$. The infiltration of dysregulated immunocytes in the skin layers and subsequent inflammation is responsible for the development of clinical plaques ${ }^{3}$. These plaques tend to be symmetrically distributed on extensor areas of scalp, elbows, trunk, and knees ${ }^{4}$.

Although this disease is not life-threatening, it has major negative impacts on the patient's psychosocial health ${ }^{5}$. Psychological distress and disability in this condition are not necessarily related to disease severity, and even mild psoriasis can have a great impact on the well-being of patients ${ }^{6}$.

In conventional medicine, topical or systemic medications and phototherapy are administered based on the severity of psoriasis. Topical therapy is the mainstay of mild psoriasis management and adjunct to systemic treatments in severe cases ${ }^{7}$. The most frequently anti-psoriasis topical drugs are corticosteroids, vitamin A derivatives, vitamin $\mathrm{D}$ analogues, calcineurin inhibitors, and coal tar. Unfortunately, most of these drugs cause unwanted side effects such as skin irritation, infections, malignancy, atrophy, purpura, telangiectasia, photosensitivity, and rebound symptoms ${ }^{8}$. Given that psoriasis is lifelong relapsing and difficult-to-treat-disorder, developing new alternative treatments with fewer side effects and higher efficacy is necessary ${ }^{9}$. In this regard, the use of traditional, complementary, and alternative (TM/CAM) modalities is promising. Recent studies have shown that the demand for such treatments among psoriasis patients has increased in the last decades ${ }^{10}$.

Iranian Traditional medicine (ITM) is one of the most ancient traditional systems of medicine with a history of thousands of years ${ }^{11}$. In ITM, plaque psoriasis is classified as a subtype of a disease named Ghouba ${ }^{12}$.

Cite this article : Kolahdooz S, Karimi M, Esmaili N, Zargaran A, Kordafshari G, Mozafari N, Ayati M H. Evaluation of the efficacy of a topical chamomile-pumpkin oleogel for the treatment of plaque psoriasis: an intra-patient, double-blind, randomized clinical trial. Biomed. Res. Ther.; 5(11):2811-2819. 
${ }^{6}$ Skin Research Center, Shahid Beheshti University of Medical Sciences, Tehran, Iran

${ }^{7}$ Department of Iranian Traditional Medicine, School of Iranian Traditional Medicine, Tehran University of Medical Sciences, Tehran, Iran
In ITM textbooks, herbal oils such as pumpkin $(\mathrm{Cu}$ curbita pepo L.) seed oil and chamomile (Matricaria chamomilla L.) oil (aqueous chamomile extract in sesame oil vehicle) are recommended for topical management of psoriasis ${ }^{13}$.

The therapeutic effects of topical chamomile on inflammatory skin conditions such as atopic eczema ${ }^{14}$, diaper rash ${ }^{15,16}$ radiation dermatitis ${ }^{17}$ and phlebitis ${ }^{18}$ have been documented in several studies. However, studies on the topical dosage forms of pumpkin seeds are limited. In an animal model of chronic skin inflammation, topical pumpkin seed oil could reduce edema, congestion, cells infiltration, and keratinocyte hyperproliferation as well as dexamethasone ${ }^{19}$.

To date, no study has investigated the therapeutic effect of topical preparations of chamomile or pumpkin seed oil on psoriasis. However, the documented anti-inflammatory effects of chamomile ${ }^{20}$ and pumpkin seed oil ${ }^{19}$ provide hypothetical support for their probable therapeutic effect on plaque psoriasis. This study was designed to evaluate the efficacy of a semisolid topical herbal preparation made from the aforementioned herbal oils $(\mathrm{ChP})$ on plaque psoriasis.

\section{METHODS}

\section{Study design}

This randomized intra-patient double-blind placebocontrolled clinical trial was conducted at the Department of Dermatology at the Razi Hospital of the Tehran University of Medical Sciences, between September 2017 and March 2018.

\section{Ethical issues}

This clinical trial was conducted in compliance with the Declaration of Helsinki. The study protocol was reviewed and approved by the Research Ethics Committee of the Tehran University of Medical Sciences (approval code: IR.TUMS.VCR.REC.1395.184). This study was registered at the Iranian Registry of Clinical Trials website (IRCT2016092830030N1). After explaining the purpose of the trial to the patient, written informed consent was obtained from each patient.

\section{Preparation of ChP oleogel and placebo}

The ChP oleogel was a mixture of traditional $M$. chamomilla oil (direct heat method), C. pepo seed oil, and colloidal silicon dioxide (47.5\%: 47.5\%: $5 \%)$. The placebo oleogel consisted of traditional $M$. chamomilla oil, C. pepo seed oil, silicon dioxide, and liquid paraffin (0.5\%: 0.5\%: 5\%: $94 \%)$. The texture, color, and smell of these two formulations were similar.
Traditional chamomile oil was prepared based on the direct heat method, which was standardized in previous studies ${ }^{21,22}$. In this method, chamomile flower was powdered and boiled in water to achieve an aqueous extract. Then, after filtering the mixture, the aqueous extract was mixed with sesame oil and then boiled to evaporate all water content. The remaining oil is called chamomile oil. Also, standard pumpkin seed oil was purchased from the Giah Essence Phytopharm Co., Iran.

\section{Inclusion and exclusion criteria}

We enrolled 40 patients of both sexes using the eligibility criteria listed in the Table 1 .

\section{Randomization and blinding}

To ensure balance in the treatment side (left or right), block randomization with a 1:1 ratio and block size of four participants was performed. The principal investigator prepared sequentially numbered, sealed, opaque envelopes for allocation of treatment. The investigators and patients remained unaware of treatment allocation. The codes of $\mathrm{ChP}$ and placebo were only revealed after the trial was completed.

\section{Intervention}

The patients first signed the written informed consent. Then symmetrical target lesions in each patient were selected to receive $\mathrm{ChP}$ or placebo, twice daily for four weeks.

\section{Outcome assessment}

A dermatologist who was blind to randomization scored the severity of erythema, scaling, and induration of plaques with an 8 -point scale $(0=$ none, $2=$ mild, $4=$ moderate, $6=$ severe, $8=$ very severe). The response to the treatment was evaluated based on the mean reduction in the erythema, scaling, induration, and PSI scores from baseline. The PSI score is the sum of erythema, scaling, and induration score, and ranges from 0 to 24 .

In addition, we used the Physician's Global Assessment (PGA) scale as follows: worse, no change (0\%), mild improvement (0-25\%), moderate improvement (25-50\%), marked improvement (50-75\%), almost clear (75-100\%), and completely clear (100\%). Photographs of the lesions were taken at baseline and the fourth week.

Patient satisfaction with the ChP and placebo was evaluated using a visual analog scale of 0 (completely dissatisfied) to 10 (completely satisfied). Additionally, the patients were asked to report all treatment-related side effects during the study. 
Table 1: Inclusion and Exclusion Criteria

\begin{tabular}{|c|c|}
\hline Inclusion criteria & Exclusion Criteria \\
\hline $\begin{array}{l}\text { 1. Diagnosis of mild to moderate plaque-type psoriasis by } \\
\text { a dermatologist } \\
\text { 2. The presence of at least two symmetric psoriasis plaques } \\
\text { 3. Age between } 20 \text { and } 60 \text { years } \\
\text { 4. Discontinuation of topical treatment for at least two } \\
\text { weeks prior to the study } \\
\text { 5. Patient consent to participate in the study }\end{array}$ & $\begin{array}{l}\text { 1. Pregnancy or lactation } \\
\text { 2. Systemic therapy or phototherapy within the last four } \\
\text { months before study } \\
\text { 3. Need to start systemic therapy during the study } \\
\text { 4. Use of medications that could induce or exacerbate pso- } \\
\text { riasis during the study } \\
\text { 5. Skin infection or malignancy in the treatment area } \\
\text { 6. History of allergic reaction to the herbal ingredients of } \\
\text { the drug } \\
\text { 7. The unwillingness of patients to continue treatment }\end{array}$ \\
\hline
\end{tabular}

\section{Statistical analysis}

A sample size of 40 was estimated by considering the significance level of $5 \%$, the power of $80 \%$, and a probable $20 \%$ drop-out rate. The statistical analysis was performed using SPSS 16. All patients who completed the study were included in the statistical analysis. A Wilcoxon's matched-pairs signed-ranks test was conducted to establish the difference between the baseline and post-treatment values and the difference between the changes in the ChP and placebo sides. All the statistical tests were two-sided with the significance level of 0.05 .

\section{RESULTS}

Of the 40 patients enrolled in our study, 37 (20 female and 17 male) completed it. Three patients withdrew from the trial due to local side effects after application of the medications. The recruitment of the patients is shown in the CONSORT flow diagram (Figure 1).

The average age of the patients was $36.8 \pm 13.3$ years (range, 20-60 years). The mean duration of the psoriasis disease was $12.11 \pm 6.2$ years (range, 2-31 years) and the mean Psoriasis Area and Severity In$\operatorname{dex}$ (PASI) score was $6.58 \pm 3.22$ (range 1.2-10.1).

Forty symmetrical target lesions were selected, in which 16 pairs were located on upper extremities and 24 pairs were located on lower extremities.

Four weeks after treatment, the average PSI score decline in the ChP group $(4.09 \pm 2.24)$ was significantly $(p=0.000)$ greater than the placebo group $(0.48 \pm$ 1.39). The mean values of the erythema, scaling, induration, and PSI scores at baseline and four weeks after treatment are summarized in Table 2.

The mean \pm SD decrease in the erythema, scaling, and induration scores were $1 \pm 1,1.80 \pm 1.1$, and $1.28 \pm$ 1.03 in the ChP group, respectively, and $0.13 \pm 0.48$, $0.17 \pm 0.87$, and $0.17 \pm 0.58$ in the placebo group, respectively. In between group comparisons, these changes were significantly $(p<0.05)$ in favor of ChP treatment.

Regarding the Physician's Global Assessment, 50\% or greater improvement at week four was seen in $35 \%$ (13/37) of the ChP treated plaques versus $0 \%$ of the placebo-treated plaques. Of the 40 plaques treated with ChP, 54\% showed moderate to marked improvement, and $14 \%$ became almost or completely clear. In the placebo group, $41 \%$ and $16 \%$ of the plaques found respectively mild and moderate improvement (Figure 2). The clinical effectiveness of the ChP is shown in figure 3 (Figure 3).

The overall patient satisfaction score on a $0-10$ VAS was $4.77 \pm 2.22$ in the $\mathrm{ChP}$ group and $1.92 \pm 1.13$ in the placebo group.

Safety was assessed by recording adverse drug reactions and patient withdrawal from the study. During the first week of treatment, three of the forty subjects enrolled experienced itching and irritation of contralateral plaques which was more severe in the $\mathrm{ChP}$ treated side. These symptoms resolved 24 hours after discontinuation of the treatments, but these patients were excluded due to an unwillingness to continue the trial. In the remaining 37 patients, the $\mathrm{ChP}$ was well tolerated without any side effect.

\section{DISCUSSION}

Topical therapy is an important part of psoriasis management especially in mild to moderate cases. Unfortunately, conventional topical drugs have side effects, which limit their long-term use ${ }^{23}$. Developing new anti-psoriasis drugs from medicinal plants could be a promising option. In this regard, we assessed the clinical efficacy of a topical preparation (ChP) containing chamomilla oil and pumpkin seed oil on mild to moderate plaque psoriasis. Because psoriasis is a multifac- 


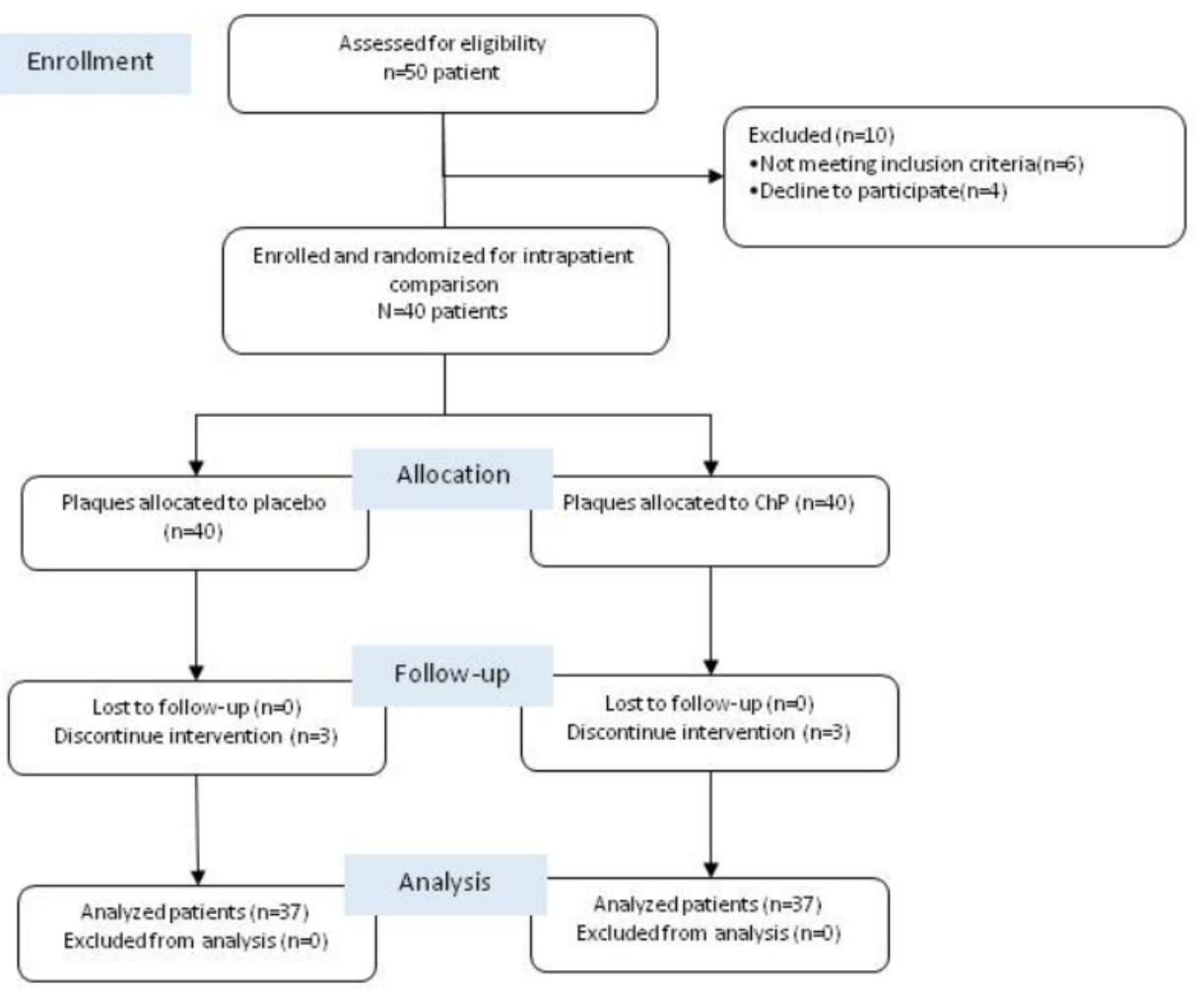

Figure 1: Consort diagram of the clinical trial.

Table 2: The mean score of erythema, scaling, in duration and PSI at Baseline and $4^{\text {th }}$ week in ChP and placebo group

\begin{tabular}{lcccc}
\hline \multicolumn{1}{c}{ Item } & Group & $\begin{array}{c}\text { Baseline }(\mathbf{n}=\mathbf{3 7}) \\
\text { mean } \pm \text { SD }\end{array}$ & $\begin{array}{c}\text { 4th week }(\mathbf{n}=\mathbf{3 7}) \\
\text { mean } \pm \text { SD }\end{array}$ & Pa \\
Erythema score & ChP & $3.44 \pm 1.36$ & $2.44 \pm 1.21$ & 0.000 \\
& placebo & $3.34 \pm 1.25$ & $3.21 \pm 1.22$ & 0.052 \\
Scaling score & ChP & $4.09 \pm 1.38$ & $2.28 \pm 1.55$ & 0.000 \\
& placebo & $3.80 \pm 1.30$ & $3.63 \pm 1.34$ & 0.170 \\
Induration score & ChP & $3.46 \pm 0.93$ & $2.17 \pm 0.96$ & 0.000 \\
& placebo & $3.27 \pm 0.95$ & $3.09 \pm 0.99$ & 0.039 \\
PSI score & ChP & $11 \pm 2.64$ & $6.90 \pm 3.04$ & 0.000 \\
& placebo & $10.42 \pm 2.71$ & $9.94 \pm 2.56$ & 0.019 \\
\hline
\end{tabular}

Pa: Pvalue of analysis in eachgroupfrom baseline to four weeks a fter treatment 


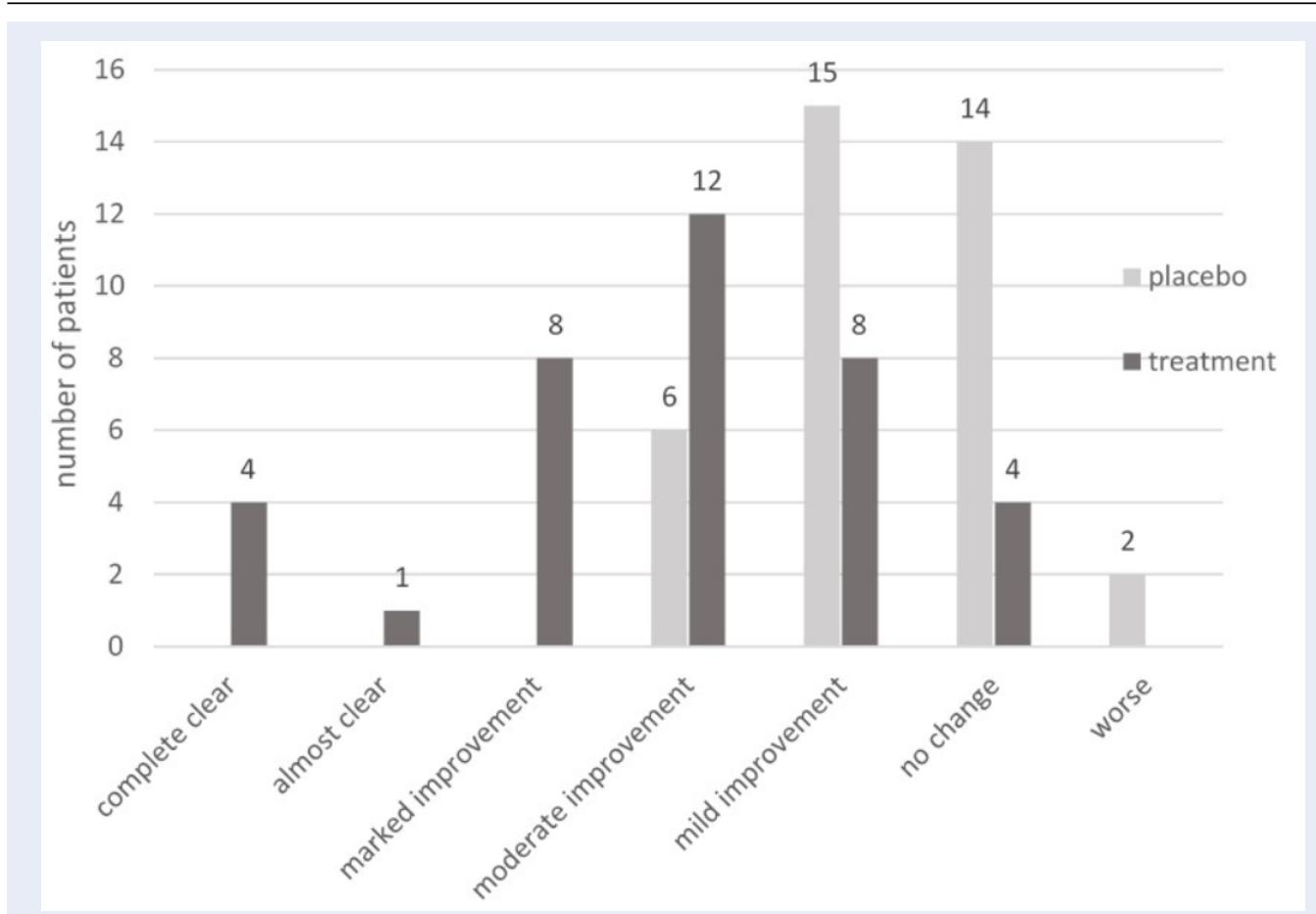

Figure 2: Physician Global Assessment of psoriasis plaque improvement after using ChP oleogel.

torial disease, we chose an intra-patient method to decrease the possible effect of variables such as sex, age, BMI, lifestyle habits, etc. on therapeutic response. This pilot study revealed that four weeks of treatment with ChP significantly improved erythema, scaling, thickness, and PSI scores compared with the placebo. Psoriasis is an immune -mediated inflammatory skin disease with a complex pathogenesis that is not completely understood. Complex interactions among keratinocytes, activated $\mathrm{T}$ cells, macrophages, neutrophils, and dendritic cells are involved in the development of this disease ${ }^{24}$. Reactions of these immune cells in skin layers induce inflammatory mediators release, reactive oxygen species (ROS) production, and cellular damage. All of these inflammatory reactions lead to keratinocyte hyperproliferation and psoriatic lesion formation ${ }^{25}$.

The effect of externally applied chamomilla preparations was investigated in several inflammatory skin conditions. In a study on patients with inflammatory dermatoses, the clinical efficacy of Kamillosan cream (containing German chamomilla extract) was equivalent to hydrocortisone and superior to diflucortolone and bufexamac ${ }^{26}$. In another study on peristomal skin lesions, the mean time for healing with a topical chamomilla solution was significantly greater than hydrocortisone ${ }^{27}$. These therapeutic effects of chamomilla could be attributed to biological ingredients including flavonoids (apigenin, luteolin, and quercetin) and terpenoids ( $\alpha$ bisabolol, chamazulene). These compounds exert anti-inflammatory effects through different mechanisms including anti-oxidant activities ${ }^{28-32}$, and inhibitory effects on the production of inflammatory mediators such as $\mathrm{LTB}_{4}$, PGE2, IL- $1 \beta$, IL-6, TNF- $\alpha$, and nitric oxide ${ }^{33-37}$. Also, sesame oil (used as a vehicle for chamomilla oil preparation) has compounds with anti-proliferative ${ }^{38}$, anti-inflammatory ${ }^{39,40}$ and anti-oxidant properties ${ }^{41}$. Additionally, both sesame oil $^{42}$ and pumpkin seed oil ${ }^{43}$ are rich in linoleic acid (LA) which is an essential fatty acid in the stratum corneum (SC) barrier structure. Recent studies revealed the relationship between skin barrier disruption and psoriasis pathogenesis ${ }^{44}$. Any defect in the SC barrier could result in keratinocyte hyperproliferation and cytokine release ${ }^{45}$.The SC consists of corneocytes embedded in an intercellular matrix. The presence of a lipid matrix rich in ceramides, cholesterol, and fatty acids is necessary for maintaining skin barrier function ${ }^{46}$. LA is the predominant fatty acid in the SC and is the main precursor of ceramides ${ }^{47}$. LA has a major role in preserving skin barrier integrity, and one of its metabolites named 13-hydroxyoctadecadienoic acid has antiproliferative properties $^{48}$. 


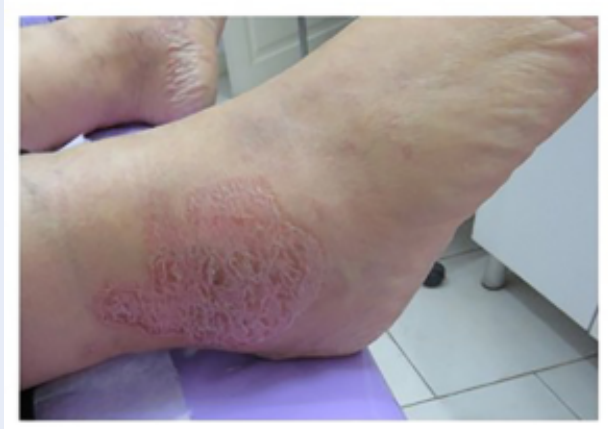

a

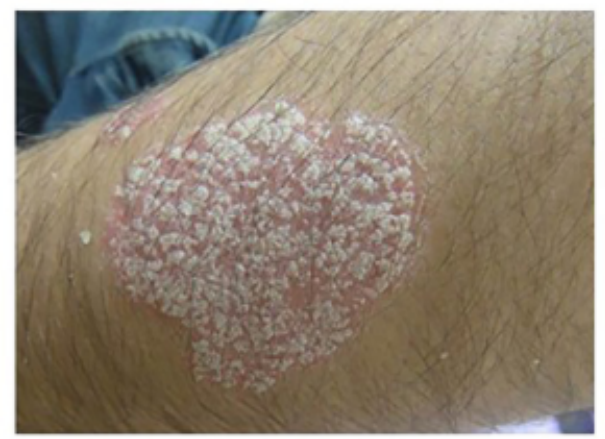

c

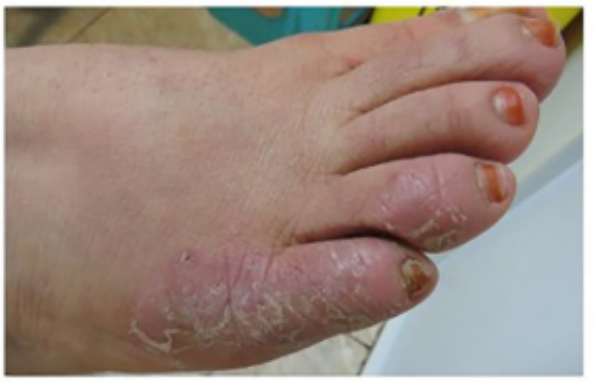

e

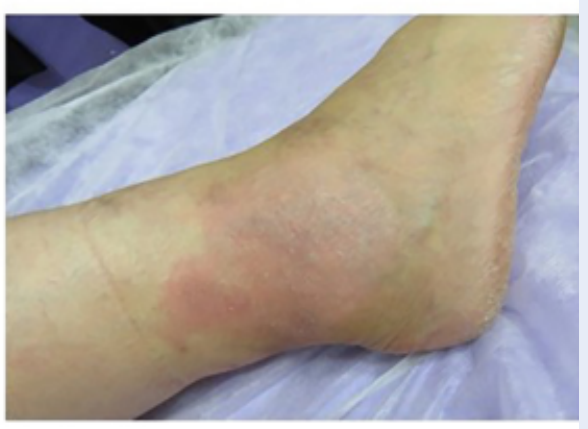

b

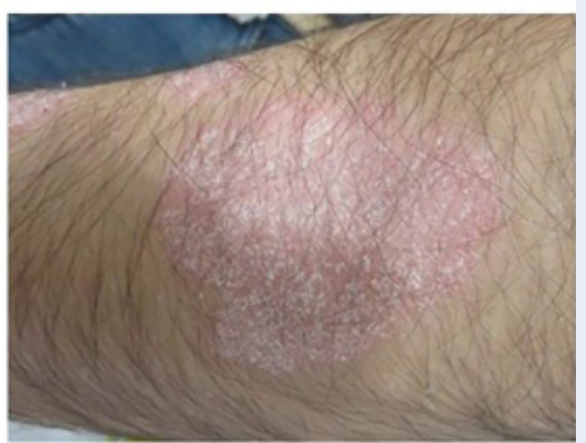

d

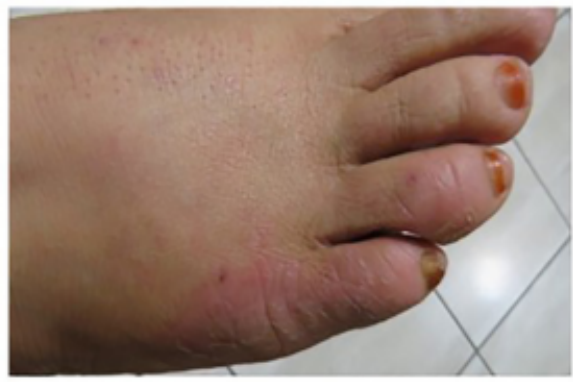

f

Figure 3: Digital photographs, at baseline (a) (c) (e) and week 4 (b) (d) (f) after application of ChP oleogel.

In addition to LA, pumpkin seed oil has a high content of tocopherols, Selenium, $\beta$ carotene, and phenolic compounds, all of which provide antioxidant effects $^{49}$.

In most of the patients, ChP was well tolerated, and no serious adverse event was reported. Three patients experienced bilateral irritation of plaque psoriasis and dropped out from the study. These side effects could be due to an allergic reaction to one of the herbal ingredients of the $\mathrm{ChP}$ and placebo. Chamomile is listed as GRAS (generally recognized as safe) by the FDA and has been used as a topical treatment in different dermatologic conditions for centuries ${ }^{50}$. Sesame seed oil is widely used in cosmetic products and the Cosmetic Ingredient Review (CIR) Expert Panel has confirmed its safety ${ }^{51}$.Although not common, allergic reactions after the topical use of Chamomile ${ }^{52-57}$ and sesame oil ${ }^{58-60}$ were documented in several case reports. Therefore, this formulation should be used with caution in patients with a history of allergic reaction to these herbs.

We acknowledge some limitations of our study in- 
cluding lack of comparison with a conventional topical anti-psoriasis drug (e.g. corticosteroid) and shortterm follow-up period.

\section{CONCLUSION}

This is the first study to evaluate the efficacy of a herbal formulation containing chamomile and pumpkin seed oil in the treatment of plaque psoriasis. Our findings suggest that $\mathrm{ChP}$ could be a safe and effective therapeutic option in mild to moderate plaque psoriasis. This therapeutic response could be related to the anti-inflammatory and antioxidant properties of the ChP ingredients. Further clinical trials with larger sample size and longer observation are needed to confirm our results and to compare the effectiveness of $\mathrm{ChP}$ with conventional anti-psoriasis drugs.

\section{COMPETING INTERESTS}

The authors state no conflict of interest.

\section{AUTHORS' CONTRIBUTIONS}

Sima Kolahdooz: study design, data acquisition, data analysis, and manuscript preparation

Mehrdad Karimi: Study design, manuscript preparation

Nafiseh Esmaili: patient recruitment and selection

Arman Zargaran: drug formulation, review and revise the manuscript

Gholamreza Kordafshari: patient recruitment

Nikoo Mozafari: patient recruitment and selection and data interpretation

Mohammad. Hossein Ayati: data analysis

All authors read the final version of article and approved it.

\section{ABBREVIATIONS}

ChP: Chamomile-pumpkin oleogel

CIR: Cosmetic Ingredient Review

GRAS: Generally recognized as safe

ITM: Iranian Traditional medicine

LA: Linoleic acid

PASI: Psoriasis Area and Severity Index

PGA: Physician's Global Assessment

PSI: Psoriasis Severity Index

ROS: Reactive oxygen species

SC: Stratum corneum

TM/CAM: Traditional, complementary, and alternative medicine

VAS: Visual analog scale

\section{REFERENCES}

1. Lima XT, Minnillo R, Spencer JM, Kimball AB. Psoriasis prevalence among the 2009 AAD National Melanoma/Skin Cancer Screening Program participants. Journal of the European Academy of Dermatology and Venereology. 2013;27:680-5. Available from: DOI:10.1111/j.1468-3083.2012.04531.x.
2. Luba KM, Stulberg DL. Chronic plaque psoriasis. South African Family Practice. 2006;73:636-44.

3. Krueger JG, Bowcock A. Psoriasis pathophysiology: current concepts of pathogenesis. Annals of the Rheumatic Diseases. 2005;64:ii30-6. Available from: DOI:10.1136/ard.2004.031120.

4. Johnson MA, Armstrong AW. Clinical and histologic diagnostic guidelines for psoriasis: a critical review. Clinical Reviews in Allergy \& Immunology. 2013;44:166-72. Available from: DOI: 10.1007/s12016-012-8305-3.

5. Kimball $A B$, Jacobson $C$, Weiss $S$, Vreeland MG, Wu Y. The psychosocial burden of psoriasis. American Journal of Clinical Dermatology. 2005;6:383-92. Available from: Doi:10.2165/ 00128071-200506060-00005.

6. Stern RS, Nijsten T, Feldman SR, Margolis DJ, Rolstad T. Psoriasis is common, carries a substantial burden even when not extensive, and is associated with widespread treatment dissatisfaction. The Journal of Investigative Dermatology Symposium Proceedings. 2004;9:136-9. Available from: DOI:10. 1046/j.1087-0024.2003.09102.x.

7. Bos JD, Spuls PI. Topical treatments in psoriasis: today and tomorrow. Clinics in Dermatology. 2008;26:432-7. Available from: DOI:10.1016/j.clindermatol.2007.10.025.

8. Kamel JG, Yamauchi PS. Managing Mild-to-Moderate Psoriasis in Elderly Patients: Role of Topical Treatments. Drugs \& Aging. 2017;34:583-8. Available from: DOI:10.1007/s40266017-0480-8.

9. Herman A, Herman AP. Topically Used Herbal Products for the Treatment of Psoriasis - Mechanism of Action, Drug Delivery, Clinical Studies. Planta Medica. 2016;82:1447-55. Available from: DOI:10.1055/s-0042-115177.

10. Smith N, Weymann A, Tausk FA, Gelfand JM. Complementary and alternative medicine for psoriasis: a qualitative review of the clinical trial literature. Journal of the American Academy of Dermatology. 2009;61:841-56. Available from: DOI:10.1016/ j.jaad.2009.04.029.

11. Rezaeizadeh $\mathrm{H}$, Alizadeh $\mathrm{M}$, Naseri M, Ardakani M. The Traditional Iranian Medicine Point of View on Health and disease. Iranian Journal of Public Health. 2009;38:169-72. null.

12. Atyabi A, Shirbeigi L, Eghbalian F. Psoriasis and topical Iranian traditional medicine. Iranian Journal of Medical Sciences. 2016;41:S54.

13. Aghili K, MH S. Qarabadin-e-Kabir. In: Qarabadin-e-Kabir; 1970. null.

14. Patzelt-Wenczler R, Ponce-Poschl E. Proof of efficacy of Kamillosan(R) cream in atopic eczema. European Journal of Medical Research. 2000;5:171-5.

15. Badelbuu SG, Javadzadeh Y, Jabraeili M, Heidari S, Bostanabad MA. Evaluation of the Effect of Aloe Vera Ointment with Chamomile Ointment on Severity of Children's Diaper Dermatitis: A randomized, double-blind clinical trial. Middle East Journal of Family Medicine. 2018;7:47.

16. Afshari $Z$, Jabraeili $M$, Asaddollahi $M$, Ghojazadeh $M$ Javadzadeh $Y$. Comparison of the effects of chamomile and calendula ointments on diaper rash. Evidence Based Care. 2015;5:49-56.

17. Maiche AG, Grohn P, Maki-Hokkonen H. Effect of chamomile cream and almond ointment on acute radiation skin reaction. Acta Oncologica (Stockholm, Sweden). 1991;30:395-6.

18. dos Reis PED, de Carvalho EC, Bueno PCP, Bastos JK. Clinical application of Chamomilla recutita in phlebitis: dose response curve study. Revista latino-americana de enfermagem. 2011;19:03-10.

19. de Oliveira ML, Nunes-Pinheiro DC, Bezerra BM, Leite LO, Tome AR, Girao VC. Topical Anti-inflammatory Potential of Pumpkin (Cucurbita pepo L.) Seed Oil on Acute and Chronic Skin Inflammation in Mice. Acta Scientiae Veterinariae. 2013;41:1-9.

20. Miraj S, Alesaeidi S. A systematic review study of therapeutic effects of Matricaria recuitta chamomile (chamomile). Electronic Physician. 2016;8:3024-31. Available from: Doi:10. 19082/3024. 
21. Zargaran A, Borhani-Haghighi A, Salehi-Marzijarani M, Faridi P, Daneshamouz S, Azadi A. Evaluation of the effect of topical chamomile (Matricaria chamomilla L.) oleogel as pain relief in migraine without aura: a randomized, double-blind, placebo-controlled, crossover study. Neurological Sciences. 2018;39:1345-53. Available from: DOI:10.1007/s10072-0183415- 1.

22. Zargaran A, Sakhteman A, Faridi P, Daneshamouz S, Akbarizadeh AR, Borhani-Haghighi A. Reformulation of Traditional Chamomile Oil: Quality Controls and Fingerprint Presentation Based on Cluster Analysis of Attenuated Total Reflectance-Infrared Spectral Data. Journal of EvidenceBased Complementary \& Alternative Medicine. 2017;22:70714. Available from: Doi:10.1177/2156587217710982.

23. Feldman SR, Horn EJ, Balkrishnan R, Basra MK, Finlay AY, McCoy $D$, et al. Psoriasis: improving adherence to topical therapy. Journal of the American Academy of Dermatology. 2008;59:1009-16. Available from: DOI:10.1016/j.jaad.2008.08. 028.

24. Cai $Y$, Fleming $C$, Yan J. New insights of $T$ cells in the pathogenesis of psoriasis. Cellular \& Molecular Immunology. 2012:9:302-9. Available from: DOI:10.1038/cmi.2012.15.

25. Zhou Q, Mrowietz U, Rostami-Yazdi M. Oxidative stress in the pathogenesis of psoriasis. Free Radical Biology \& Medicine. 2009;47:891-905. Available from: DOI:10.1016/j. freeradbiomed.2009.06.033.

26. Aertgeerts $P$, Albring $M$, Klaschka $F$, Nasemann T, PatzeltWenczler R, Rauhut K. [Comparative testing of Kamillosan cream and steroidal $(0.25 \%$ hydrocortisone, $0.75 \%$ fluocortin butyl ester) and non-steroidal ( $5 \%$ bufexamac) dermatologic agents in maintenance therapy of eczematous diseases]. Zeitschrift fur Hautkrankheiten. 1985;60:270-7.

27. Charousaei F, Dabirian A, Mojab F. Using chamomile solution or a $1 \%$ topical hydrocortisone ointment in the management of peristomal skin lesions in colostomy patients: results of a controlled clinical study. Ostomy/Wound Management. 2011;57:28-36.

28. Stanojevic LP, Marjanovic-Balaban ZR, Kalaba VD, Stanojevic JS, Cvetkovic DJ. Chemical composition, antioxidant and antimicrobial activity of chamomile flowers essential oil (Matricaria chamomilla L.). Journal of Essential Oil Bearing Plants. 2016;19:2017-2028.

29. Roby MH, Sarhan MA, Selim KA, Khalel KI. Antioxidant and antimicrobial activities of essential oil and extracts of fennel (Foeniculum vulgare L.) and chamomile (Matricaria chamomilla L.). Industrial Crops and Products. 2013;44:43745. Available from: DOI:10.1016/j.indcrop.2012.10.012.

30. Owlia P, Rasooli I, Saderi H. Antistreptococcal and antioxidant activity of essential oil from Matricaria chamomilla L. Research Journal of Biological Sciences. 2007;2:237-9.

31. Osman MY, Taie HA, Helmy WA, Amer H. Screening for antioxidant, antifungal, and antitumor activities of aqueous extracts of chamomile (Matricaria chamomilla). Egyptian Pharmaceutical Journal. 2016;15:55.

32. Kolodziejczyk-Czepas J, Bijak M, Saluk J, Ponczek MB, Zbikowska HM, Nowak P. Radical scavenging and antioxidant effects of Matricaria chamomilla polyphenolicpolysaccharide conjugates. International Journal of Biological Macromolecules. 2015;72:1152-8. Available from: DOI:10.1016/j.ijbiomac.2014.09.032.

33. Bhaskaran N, Shukla S, Srivastava JK, Gupta S. Chamomile: an anti-inflammatory agent inhibits inducible nitric oxide synthase expression by blocking RelA/p65 activity. International Journal of Molecular Medicine. 2010;26:935-40.

34. Safayhi H, Sabieraj J, Sailer ER, Ammon HP. Chamazulene: an antioxidant-type inhibitor of leukotriene B4 formation. Planta Medica. 1994;60:410-3. Available from: DOI:10.1055/s-2006959520.

35. Srivastava JK, Pandey M, Gupta S. Chamomile, a novel and selective COX-2 inhibitor with anti-inflammatory activity. Life Sciences. 2009;85:663-9. Available from: DOI:10.1016/j.lfs. 2009.09.007.
36. Curra M, Martins MA, Lauxen IS, Pellicioli AC, Filho MS, Pavesi VC. Effect of topical chamomile on immunohistochemical levels of IL-1? and TNF-? in 5-fluorouracil-induced oral mucositis in hamsters. Cancer Chemotherapy and Pharmacology. 2013;71:293-9. Available from: DOI:10.1007/s00280012-2013-9.

37. Maurya AK, Singh M, Dubey V, Srivastava S, Luqman S, Bawankule DU. ?-(-)-bisabolol reduces pro-inflammatory cytokine production and ameliorates skin inflammation. Current Pharmaceutical Biotechnology. 2014;15:173-81. Available from: Doi:10.2174/1389201015666140528152946.

38. Zhou L, Lin X, Abbasi AM, Zheng B. Phytochemical contents and antioxidant and antiproliferative activities of selected black and white sesame seeds. BioMed research international. 2016;2016.

39. Monteiro EM, Chibli LA, Yamamoto CH, Pereira MC, Vilela FM, Rodarte MP. Antinociceptive and anti-inflammatory activities of the sesame oil and sesamin. Nutrients. 2014;6:1931-44. Available from: DOI:10.3390/nu6051931.

40. Hsu DZ, Chu PY, Liu MY. Sesame seed (Sesamum indicum L.) extracts and their anti-inflammatory effect; 2012.

41. Carvalho R, Galvao E, Barros J, Conceicao M, Sousa E. Extraction, fatty acid profile and antioxidant activity of sesame extract (Sesamum Indicum L.). Brazilian Journal of Chemical Engineering. 2012;29:409-20. Available from: Doi:10.1590/ s0104-66322012000200020.

42. Yol E, Toker R, Golukcu M, Uzun B. Oil Content and Fatty Acid Characteristics in Mediterranean Sesame Core Collection. Crop Science. 2015;55:2177. Available from: DOI:10 2135/cropsci2014.11.0771.

43. Ardabili AG, Farhoosh R, Khodaparast MHH. Chemical composition and physicochemical properties of pumpkin seeds $(\mathrm{Cu}$ curbita pepo subsp. pepo var. Styriaka) grown in Iran. Journal of Agricultural Science and Technology. 2011;13:1053-63.

44. Sano S. Psoriasis as a barrier disease. Zhonghua Pifuke Yixue Zazhi. 2015;33:64-9. Available from: DOI:10.1016/j.dsi.2015. 04.010

45. Ye L, Lv C, Man G, Song S, Elias PM, Man MQ. Abnormal epidermal barrier recovery in uninvolved skin supports the notion of an epidermal pathogenesis of psoriasis. The Journal of Investigative Dermatology. 2014;134:2843-6. Available from: DOI:10.1038/jid.2014.205.

46. Menon GK, Cleary GW, Lane ME. The structure and function of the stratum corneum. International Journal of Pharmaceutics. 2012;435:3-9. Available from: DOI:10.1016/j.ijpharm.2012.06. 005.

47. McCusker MM, Grant-Kels JM. Healing fats of the skin: the structural and immunologic roles of the ?-6 and ?-3 fatty acids. Clinics in Dermatology. 2010;28:440-51. Available from: DOI: 10.1016/j.clindermatol.2010.03.020.

48. Ziboh VA, Miller CC, Cho Y. Metabolism of polyunsaturated fatty acids by skin epidermal enzymes: generation of antiinflammatory and antiproliferative metabolites. The American Journal of Clinical Nutrition. 2000;71:361S-6S. Available from: DOI:10.1093/ajcn/71.1.361s.

49. Eraslan G, Kanbur M, Aslan O, Karabacak M. The antioxidant effects of pumpkin seed oil on subacute aflatoxin poisoning in mice. Environmental Toxicology. 2013:28:681-8. Available from: DOI:10.1002/tox.20763.

50. Srivastava JK, Shankar E, Gupta S. Chamomile: A herbal medicine of the past with bright future. Molecular Medicine Reports. 2010;3:895-901.

51. Johnson W, Bergfeld WF, Belsito DV, Hill RA, Klaassen $C D$ Liebler DC, et al. Amended safety assessment of sesamum indicum (sesame) seed oil, hydrogenated sesame seed oil, sesamum indicum (sesame) oil unsaponifiables, and sodium sesameseedate. International journal of toxicology. 2011;30:40S-53S.

52. Foti C, Nettis E, Panebianco R, Cassano N, Diaferio A, Pia DP. Contact urticaria from Matricaria chamomilla. Contact Dermatitis. 2000;42:360-1. 
53. McGeorge BC, Steele MC. Allergic contact dermatitis of the nipple from Roman chamomile ointment. Contact Dermatitis. 1991;24:139-40. Available from: DOI:10.1111/j.1600-0536. 1991.tb01672.x.

54. Ozden MG, Denizli H, Aydin F, Senturk N, Canturk T, Turanli AY. Allergic concact dermatitis from chamomile plant. Journal of Experimental and Clinical Medicine. 2011;28:29-30. Available from: DOI:10.5835/jecm.omu.28.1.008.

55. van Ketel WG. Allergy to Matricaria chamomilla. Contact Dermatitis. 1982;8:143. Available from: DOI:10.1111/j.1600-0536. 1982.tb04170.x.

56. Rudzki E, Rapiejko P, Rebandel P. Occupational contact dermatitis, with asthma and rhinitis, from camomile in a cosmetician also with contact urticaria from both camomile and lime flowers. Contact Dermatitis. 2003:49:162. Available from: DOI:10.1111/j.0105-1873.2003.0185e.x.
57. Pereira F, Santos R, Pereira A. Contact dermatitis from chamomile tea. Contact Dermatitis. 1997;36:307. Available from: DOI:10.1111/j.1600-0536.1997.tb00008.x.

58. Oiso N, Yamadori Y, Higashimori N, Kawara S, Kawada A. Allergic contact dermatitis caused by sesame oil in a topical Chinese medicine, shi-un-ko. Contact Dermatitis. 2008;58:109. Available from: DOI:10.1111/j.1600-0536.2007.01175.x.

59. Kubo Y, Nonaka S, Yoshida H. Contact sensitivity to unsaponifiable substances in sesame oil. Contact Dermatitis. 1986;15:215-7. Available from: DOI:10.1111/j.1600-0536. 1986.tb01339.x.

60. Pecquet C, Leynadier F, Saiag P. Immediate hypersensitivity to sesame in foods and cosmetics. Contact Dermatitis. 1998;39:313. Available from: DOI:10.1111/j.1600-0536.1998. tb05948.x. 